\title{
A Palaeogene record of the ionic composition of seawater and its relationship to atmospheric $\mathrm{CO}_{2}$
}

\author{
DAVID EVANS ${ }^{1}$, YAIR ROSENTHAL ${ }^{2}$, JONATHAN EREZ ${ }^{3}$, \\ HAGAR HAUZER $^{3}$, LAURA COTTON ${ }^{4}$, XIAOLI ZHOU ${ }^{5}$, \\ PETER STASSEN $^{6}$, PAUL PEARSON $^{7}$, WILLEM RENEMA ${ }^{8}$, \\ PRATUL KUMAR SARASWATI ${ }^{9}$, JONATHAN TODD ${ }^{10}$, \\ WOLFGANG MÜLLER ${ }^{1}$ AND HAGIT P. AFFEK ${ }^{3}$ \\ ${ }^{1}$ Institute of Geosciences, Goethe University \\ ${ }^{2}$ Rutgers University \\ ${ }^{3}$ The Fredy \& Nadine Herrmann Institute of Earth Sciences, the \\ Hebrew University of Jerusalem \\ ${ }^{4}$ University of Portsmouth \\ ${ }^{5}$ Tongji University \\ ${ }^{6} \mathrm{KU}$ Leuven \\ ${ }^{7}$ Cardiff University \\ ${ }^{8}$ Naturalis Biodiversity Center \\ ${ }^{9}$ Indian Institute of Technology Bombay \\ ${ }^{10}$ Natural History Museum \\ Presenting Author: evans@em.uni-frankfurt.de
}

Knowledge of the past major and minor ion composition of seawater is key to unravelling the role of large-scale geologic processes such as silicate weathering and fluid-rock interaction in driving long-term climate change. In addition, precise seawater chemistry reconstructions are a prerequisite of the application of carbonate mineral trace element thermometers in deep time. However, with the exception of reconstructions based on the analysis of fluid inclusions trapped in evaporitic sequences, a direct proxy for the past concentration of key elements in seawater is lacking. Recently [1], it was shown that the $\mathrm{Na} / \mathrm{Ca}$ ratio of foraminiferal calcite can be used as a direct proxy for seawater [Ca], because $\mathrm{Na}$ has an extremely long residence time such that changes in calcite $\mathrm{Na} / \mathrm{Ca}$ are principally driven by [Ca]. Here, we apply this relationship to a suite of exceptionally well-preserved fossil larger benthic foraminifera spanning the Eocene and early Oligocene. This record demonstrates that early Eocene seawater $[\mathrm{Ca}]$ was $\sim 2 \times$ modern and decreased through the Palaeogene. By coupling these [Ca] reconstructions with existing data regarding the evolution of seawater elemental ratios (e.g. $\mathrm{Mg} / \mathrm{Ca}, \mathrm{Sr} / \mathrm{Ca}$ ), we furthermore reconstruct changes in seawater $[\mathrm{Mg}]$ and $[\mathrm{Sr}]$, demonstrating a modest increase in seawater $[\mathrm{Mg}]$ and a $[\mathrm{Sr}]$ decrease that almost exactly mirrors that of [Ca]. Finally, coupling our data with existing reconstructions of atmospheric $\mathrm{CO}_{2}$ indicates a close correspondence in the timing of seawater chemistry and $\mathrm{CO}_{2}$ changes, and we explore how this coincident variation might be explained.

[1] Hauzer, H. et al. [2018] EPSL 497: 80. 